Vol. 4 No.2 Juni 2021

http://jurnal.umsb.ac.id/index.php/RANGTEKNIKJOURNAL

\title{
Analisis Perbandingan Unjuk Kerja Turbin PLTA Batang Agam Terhadap Kondisi Pada Saat Komisioning
}

\author{
Hariadi $^{1}$, Muchlisinalahuddin ${ }^{2}$, Mira Meilisa $^{3}$ \\ Teknik Mesin, Fakultas Teknik, Universitas Muhammadiyah Sumatera Barat ${ }^{1,2,3}$ \\ Email: hariadi05@gmail.com ${ }^{1}$, Muchlisinalahuddin.umsb@gmail.com ${ }^{2}$, miecko7@gmail.com ${ }^{3}$ \\ DOI: http://dx.doi.org/10.31869/rtj.v4i2.2667
}

\begin{abstract}
: the batang agam hydroelectric power plant is the oldest hydroelectric power plant in west sumatera, which is located in the district of lima puluh kota. The hydroelectric power plant started operating in 1976 with a nett power is $10.5 \mathrm{mw}$. In its operation so far the turbine of the batang agam hydroelectric power plant decrease in the performance compared to the initial commissioning. The impact of decreasing turbine efficiency of batang agam hydroelectric power plant lead use of water to convert its energy electricity be wasteful. Therefore it is necessary to research so that the turbine can effectively use the river water that has been dammed in the kolam tando more efficient.

From the results of analysis obtained the conclusion that the efficiency of the turbine Batang Agam Hydroelectric Power Plant at 3.5 MW from the highest to the lowest; Unit 1 with $86.7 \%$ efficiency, Unit 3 with $83.9 \%$ efficiency and Unit 2 with $79.2 \%$ efficiency. Compared with commissioning data unit-units in the turbine of Batang Agam Hydroelectric Power Plant has decreased efficiency of the amount; Unit 1 of $0.32 \%$, Unit 2 of $7.80 \%$ and Unit 3 is $3.05 \%$.
\end{abstract}

Keyword: Water turbine, Francis, Flow, Efficiency, Performance.

\section{PENDAHULUAN}

PLTA Batang Agam merupakan PLTA tertua di Sumatera Barat yang berwilayah di Kabupaten Lima Puluh Kota. PLTA ini mulai beroperasi pada tahun 1976 dengan memanfaatkan potensi air sungai Batang Agam yang dibendung dan dialirkan menuju Kolam Tando dan diteruskan melalui terowongan headrace tunnel sepanjang 1.080 $m$ untuk memutar turbin generator pada powerhouse. PLTA Batang Agam memiliki daya terpasang 10,5 MW yang terdiri dari 3 unit mesin pembangkit. PLTA Batang Agam memiliki beberapa peralatan utama, yaitu: Turbin, Generator dan Transformator.

Dalam operasinya selama ini Turbin PLTA Batang Agam mengalami penurunan unjuk kerja dibandingkan pada saat awal komisioning. Terdapat beberapa parameter operasi yang mempengaruhi dari unjuk kerja turbin PLTA Batang Agam, yaitu: Head dan Debit.

Pengaruh dari efisiensi turbin PLTA Batang Agam yang turun menyebabkan penggunaan air untuk diubah energinya menjadi listrik menjadi boros, sehingga pendistribusian listrik ke masyarakat tidak maksimal. Oleh itu diperlukan penelitian agar turbin dapat efektif penggunaan air sungai yang telah dibendung di Kolam Tando lebih efisien.
Dengan latar belakang diatas penulis akan melakukan penelitian dengan judul "Analisis Perbandingan Unjuk Kerja Turbin Plta Batang Agam Terhadap Kondisi Pada Saat Komisioning"

\section{TINJAUAN PUSTAKA Turbin Air}

Turbin air adalah piranti yang mengambil tenaga (daya) dari suatu fluida atau turbin air adalah turbin dengan air sebagai fluida kerjanya. Setelah peristiwa perubahan energi potensial menjadi energi kinetik secara berangsur-angsur melalui pipa pesat atau saluran selanjutnya air memutar sudu-sudu jalan (runner). Oleh runner energi kinetik dirubah menjadi energi mekanik yang selanjutnya diteruskan oleh poros turbin.

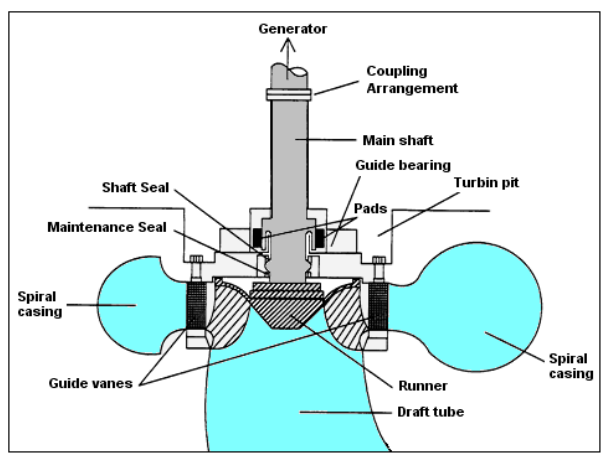

Gambar 1 Potongan Turbin Air

Ditinjau dari kedudukan porosnya turbin air dibagi menjadi dua macam: 
1) Turbin horisontal

2) Turbin vertikal

Ditinjau dari fluida kerjanya dibagi menjadi dua macam:

1) Turbin Reaksi

Turbin reaksi adalah turbin air yang melewati runner mengalami penurunan tekanan baik pada sudu pengatur maupun pada runner. Contoh: Turbin Francis, Propeller dan Kaplan.

2) Turbin Impuls

Turbin Impuls adalah turbin air dimana proses penurunan tekanan airnya terutama terjadi didalam distributor/nozlenya dan tidak terjadi pada sudu-sudu jalannya. Contoh: Turbin Pelton.

Turbin francis termasuk salah satu turbin reaksi, artinya fluida yang bekerja mengubah tekanan bersamaan dengan gerak dari turbin tersebut, yang menghasilkan energi. Turbin Francis umumnya digunakan pada unit pembangkit dengan tinggi jatuh sedang Gambar 2 menunjukkan penampang melintang turbin francis.

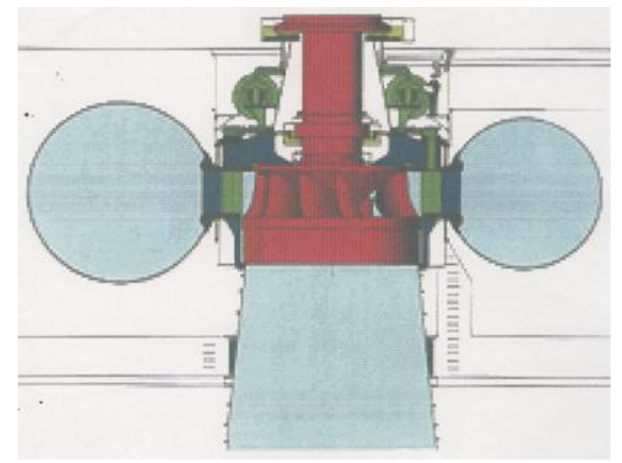

Gambar 2 Potongan Penampang Turbin

Francis

Kecepatan air yang masuk kedalam turbin Francis tergantung pada tinggi jatuh dan juga aliran yang melalui sudu pengatur (guide vane atau wicket gate). Kemudian air mengalir melalui runner dan akhimya dibuang menuju pipa hisap (draft tube) semua laluan berisi penuh oleh air yang menggerakkan runner.

Turbin air mempunyai beberapa bagian-bagian komponen utama yang penting, yaitu:

1) Sudu jalan (runner)

Berfungsi untuk merubah energi kinetik menjadi energi mekanik berupa putaran poros turbin.

Runner pada turbin francis dan propeller letak daun sudunya tetap, sedangkan pada turbin kaplan sudut pemasukkan sudu runner dan sudut keluarnya bisa diubah-ubah (diatur) dengan tujuan agar runner bisa secara cepat dan langsung mengimbangi respon air bila terjadi perubahan kecepatan air, sehingga putaran poros turbin tetap stabil.

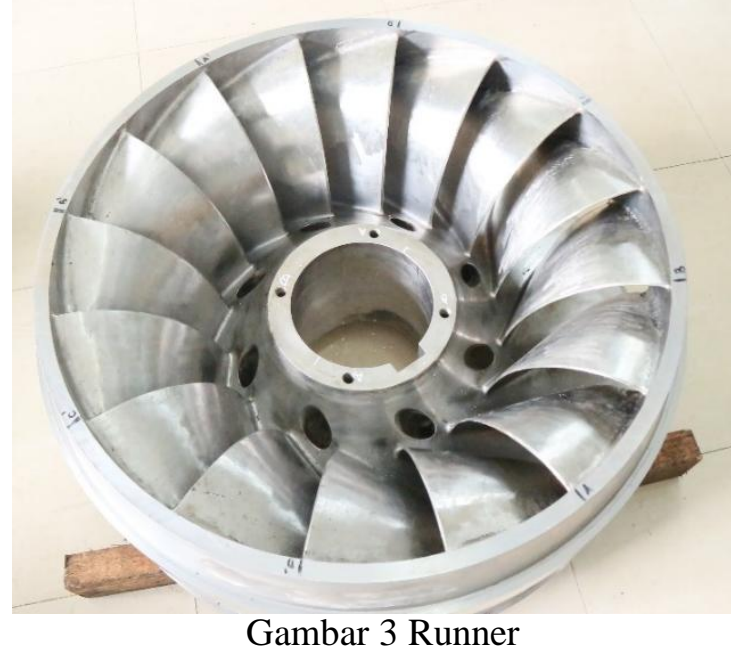

2) Kasing spiral (spiral case)

Spiral case berfungsi untuk mengumpulkan, mendistribusikan dan mengarahkan aliran ke arah guide vane dan selanjutnya ke arah sudusudu pada runner untuk menghasilkan daya keluaran turbin yang optimal. Dengan bentuknya seperti rumah keong, maka distribusi tekanan dan kecepatan air akan sama di seluruh guide vanes.

Spiral case mempunyai 1 manhole dengan diameter $500 \mathrm{~mm}$ dan tutupnya dirancang agar membuka kearah luar yang berfungsi untuk inspeksi didalam spiral case. Gantungan luar tutup manhole dan kaki-kaki gantungan terbuat dari baja. Disekeliling tutup manhole dilapisi karet dengan diamater ketebalan $6 \mathrm{~mm}$ dan menyatu dengan mur dan baut untuk keperluan perapat (sealing).

Saat tutup manhole dibuka untuk pemeliharaan, karet pelapis tutup harus diganti dengan yang baru waktu tutup dipasang kembali untuk menjaga kekuatan seal yang baik. 

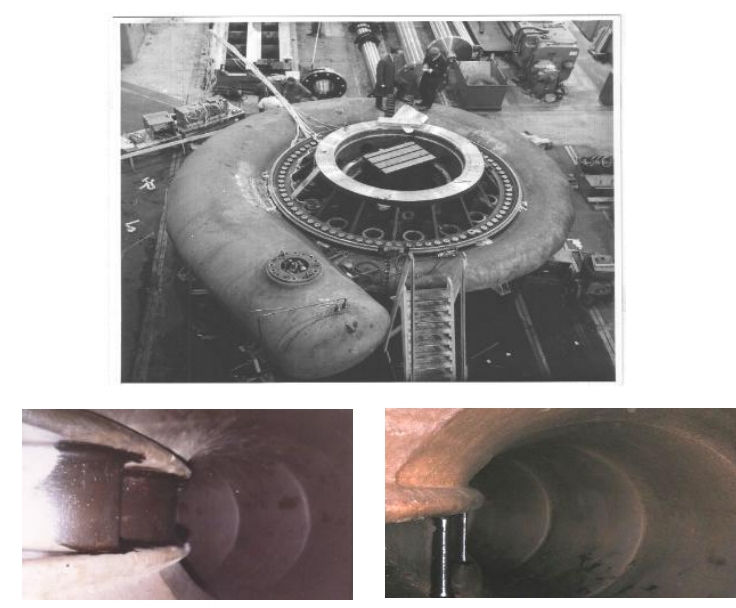

Gambar 4 Spiral Casing

\section{Alat Ukur}

Pengukuran merupakan suatu aktifitas dan atau tindakan membandingkan suatu besaran yang belum diketahui nilainya atau harganya terhadap besaran lain yang sudah diketahui nilainya, misalnya dengan besaran standart.

Pekerjaan membandingkan tersebut tiada lain adalah pekerjaan pengukuran atau mengukur. Sedangkan pembandingnya yang disebut sebagai alat ukur. Pengukuran banyak sekali dilakukan dalam bidang teknik atau industri. Sedangkan alat ukurnya sendiri banyak sekali jenisnya, tergantung dari banyak faktor, misalnya objek yang diukur serta hasil yang diinginkan. Yang perlu diperhatikan dalam melakukan pengukuran adalah:

1) Standar yang dipakai harus memiliki ketelitian yang sesuai dengan standart yang telah ditentukan.

2) Tata cara pengukuran dan alat yang digunakan harus memenuhi persyaratan.

Pengetahuan yang harus dimiliki adalah bagaimana menetukan besaran yang akan diukur, bagaimana mengukurnya dan mengetahui dengan apa besaran tersebut harus diukur. Ketiga hal tersebut harus mutlak dimiliki oleh orang yang akan melakukan pengukuran.

Efisiensi atau unjuk kerja turbin tidak tetap nilainya, tergantung dari keadaan beban dan jenis turbinnya. Kinerja dari suatu turbin dapat dinyatakan dalam beberapa keadaan: tinggi terjun maksimum, tinggi terjun minimum, tinggi terjun normal, dan tinggi terjun rancangan. Pada tinggi terjun rancangan turbin akan memberikan kecepatan terbaiknya sehingga efisiensinya mencapai maksimum.
Dalam tabel 2.1 disajikan efisiensi turbin untuk berbagai kondisi sebagai gambaran mengenai kisaran nilai efisiensi terhadap beban dan jenis turbin.

Tabel 1 Efisiensi Turbin untuk Berbagai Kondisi Beban

\begin{tabular}{|c|c|c|c|c|c|c|c|}
\hline \multirow[t]{2}{*}{ Jenis Tarthin } & \multirow[t]{2}{*}{$\mathrm{N}$} & \multicolumn{5}{|c|}{ 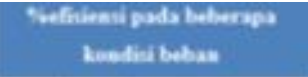 } & \multirow{2}{*}{ 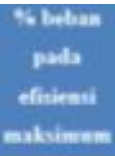 } \\
\hline & & 0.25 & 0.50 & 0.75 & 1 & maks & \\
\hline Impols (Pethen) & 22 & 81 & 85 & 87 & 85 & 87,1 & 70 \\
\hline Ftrancia & 75 & 62 & 83 & 88 & 83 & 58 & 75 \\
\hline Francin & 110 & 60 & 85 & 90 & 84 & 90,2 & 50 \\
\hline Francis & 230 & 59 & $\mathbf{8 3}$ & 90 & 85 & 91.5 & 15 \\
\hline Frascis & 335 & 34 & 82 & 91 & 86 & 91,0 & 87,5 \\
\hline Francis & 410 & 47 & $\pi \cdot 5$ & 85 & 87 & 91,5 & 92,5 \\
\hline Francia & 460 & 55 & 74.5 & 86,5 & ss & 92,5 & 92 \\
\hline Phopeller (eads tetap) & 600 & 45 & $x$ & 84,5 & 82 & 91,5 & 92 \\
\hline Propeller (walu tetap) & 500 & 32 & 59 & $\pi$ & s4 & 58 & 96 \\
\hline 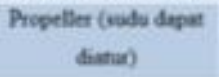 & 750 & 53.5 & 91 & 915 & 87 & 91.6 & 70 \\
\hline
\end{tabular}

Penghitungan Efisiensi Turbin

1) Daya Air

Daya yang masuk ke dalam turbin francis adalah daya potensial air.

Phid $=\rho \times g \times Q \times H$

Dimana:

Phid : Daya hidrolis air (Watt)

$\rho \quad:$ Massa jenis air $\left(\mathrm{kg} / \mathrm{m}^{3}\right)$

g : Percepatan gravitasi $\left(\mathrm{m}^{3} / \mathrm{s}\right)$

Q : Laju aliran massa $\left(\mathrm{m}^{3} / \mathrm{s}\right)$

$\mathrm{H} \quad$ : Head dari tinggi jatuh air $(\mathrm{mH} 2 \mathrm{O})$

2) Daya Keluar Turbin

Daya yang dikeluarkan oleh turbin adalah daya poros karena tujuan turbin adalah mengubah energi kinetik menjadi energi mekanis.

$$
\mathrm{P}_{\mathrm{tur}}=\frac{2 \mathrm{x} \pi \mathrm{xn \times T}}{60}
$$

Dimana:

$\mathrm{P}_{\text {tur }} \quad$ : Daya Mekanis (Watt)

$\mathrm{n} \quad$ : kecepatan putar turbin (rpm)

$\mathrm{T} \quad$ : Torsi $(\mathrm{Nm})=\mathrm{F} \times \mathrm{s}$

3) Efisiensi Turbin

Efisiensi turbin didapatkan dari membandingkan daya mekanik dengan daya air.

$$
\eta=\frac{\text { Daya Mekarik }}{\text { Daya Air }} \times 100 \%
$$


Vol. 4 No.2 Juni 2021

Rang Teknik Journal

http://jurnal.umsb.ac.id/index.php/RANGTEKNIKJOURNAL

METODE PENELITIAN

Diagram Alir Penyusunan Laporan Akhir

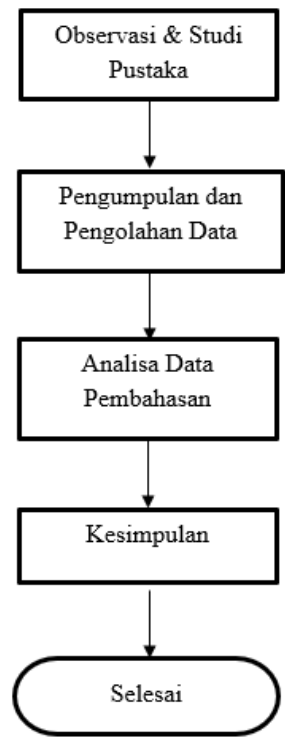

Waktu dan Tempat Pengambilan Data

Pengambilan data penelitian ini dilakukan di PT. PLN (Persero) Unit Pelaksana Pembangkitan (UPK) Bukittinggi, PLTA Batang Agam Unit 1, 2 \& 3. Studi pustaka dilakukan di PLTA Batang Agam, buku manual terkait, data yang ada pada Central Control Room (CCR), serta silabus yang berkaitan dengan turbin air.

Data yang digunakan sebagai bahan penelitian merupakan parameter terukur pada panel turbin PLTA Batang Agam yang diambil pada berbagai periode operasi dan data pada saat awal commisioning test. Data tersebut akan digunakan untuk menghitung efisiensi, maka data yang dibutuhkan adalah daya yang dibangkitkan, head kolam tando dan debit fluida masuk turbin.

\subsection{Kebutuhan Data}

Untuk membantu kelancaran penelitian, dalam pembahasan ini membutuhkan beberapa data yang digunakan untuk mendapatkan hasil dari perhitungan efisiensi turbin PLTA Batang Agam. Data - datanya adalah sebagai berikut:

1) Data awal commisioning test dengan berbagai macam jenis kondisi pola operasi.

2) Data 1 hari operasi pada logsheet dari tanggal 19 Mei 2019 meliputi daya mampu (MW), head (m) dan debit ( $\mathrm{m}^{3} /$ detik).

\section{Analisis Data}

Setelah dilakukan pengambilan data dan pengolahan data. Maka penyajian data - data tersebut dapat kita analisa dan diambil kesimpulan sesuai dengan logika dan data yang tersedia.

\section{PEMBAHASAN DAN ANALISA DATA} Spesifikasi Turbin Air PLTA Batang Agam

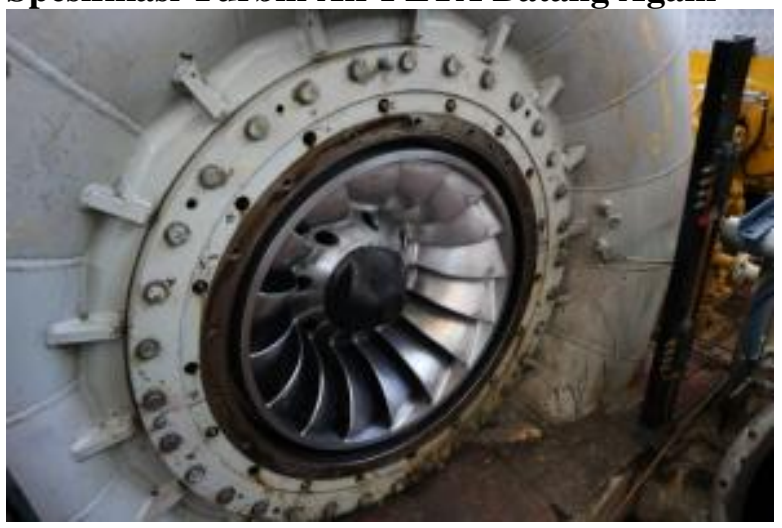

Gambar 5 Turbin tipe Francis PLTA Batang Agam

Spesifikasi dari 3 Unit turbin air PLTA Batang Agam adalah sebagai berikut:

Tabel 2 Spesifikasi turbin air plta batang agam

\begin{tabular}{|c|c|}
\hline Manufacturer & Ebara Mfg. Co. \\
\hline Type & $\begin{array}{l}\text { Horizontal Shaft. Francis } \\
\text { Type }\end{array}$ \\
\hline Effective Head & $\begin{array}{l}\text { Max : } 98,7 \mathrm{~m} \\
\text { Normal : } 90,8 \mathrm{~m} \\
\text { Min : } 89,0 \mathrm{~m}\end{array}$ \\
\hline Output & $\begin{array}{l}\text { Max : } 3900 \mathrm{~kW} \\
\text { Normal : } 3500 \mathrm{~kW} \\
\text { Min : } 3350 \mathrm{~kW}\end{array}$ \\
\hline Discharge & $\begin{array}{l}\text { Max : } 4,60 \mathrm{~m}^{3} / \mathrm{s} \\
\text { Normal }: 4,49 \mathrm{~m}^{3} / \mathrm{s} \\
\text { Min : } 4,40 \mathrm{~m}^{3} / \mathrm{s}\end{array}$ \\
\hline Rated Speed & $750 \mathrm{rpm}$ \\
\hline Runaway Speed & $1330 \mathrm{rpm}$ \\
\hline
\end{tabular}

\section{Pengambilan Data}

Data Komisioning

Komisioning tes adalah tes terakhir yang dilakukan setelah keseluruhan peralatan termasuk turbin dan generator di PLTA Batang Agam dipasang dan akan dilihat unjuk kerjanya pada tahun 1976. Berikut terdapat Tabel 4.2 yang merupakan data komisioning PLTA Batang Agam dari berbagai macam pola operasi: 
Tabel 3 Data Komisioning PLTA Batang

Agam

\begin{tabular}{|c|c|c|c|c|c|c|}
\hline \multirow{2}{*}{$\begin{array}{c}\text { Gross } \\
\text { Head } \\
\text { (m) }\end{array}$} & \multicolumn{3}{|c|}{1 Turbin Operasi } & \multicolumn{3}{|c|}{3 Turbin Operasi } \\
\hline & $\begin{array}{c}\text { Net } \\
\text { Head } \\
(\mathrm{m})\end{array}$ & $\begin{array}{c}\text { Debit } \\
\text { (m3/detik) }\end{array}$ & $\begin{array}{c}\text { Efisiensi } \\
(\%)\end{array}$ & $\begin{array}{c}\text { Net } \\
\text { Head } \\
(\mathrm{m})\end{array}$ & $\begin{array}{c}\text { Debit } \\
\text { (m3/detik) }\end{array}$ & $\begin{array}{c}\text { Efficiency } \\
(\%)\end{array}$ \\
\hline \multicolumn{7}{|c|}{ Turbine Output $=3,5 \mathrm{MW}$} \\
\hline 99,5 & 98,7 & 4,11 & 88 & 93,1 & 4,37 & 87,8 \\
\hline 97,5 & 96,7 & 4,19 & 88,1 & 90,8 & 4,49 & 87,6 \\
\hline 95,5 & 94,7 & 4,29 & 87,9 & 89 & 4,4 & 87,3 \\
\hline \multicolumn{7}{|c|}{ Turbine Output $=3,15 \mathrm{MW}$} \\
\hline 99,5 & 98,7 & 3,74 & 87,1 & 93,1 & 3,95 & 87,5 \\
\hline 97,5 & 96,7 & 3,8 & 87,4 & 90,8 & 4,05 & 87,5 \\
\hline 95,5 & 94,7 & 3,88 & 87,5 & 89 & 4,14 & 87,3 \\
\hline \multicolumn{7}{|c|}{ Turbine Output $=2,8 \mathrm{MW}$} \\
\hline 99,5 & 98,7 & 3,39 & 85,5 & 93,1 & 3,56 & 86,3 \\
\hline 97,5 & 96,7 & 3,44 & 86 & 90,8 & 3,64 & 86,5 \\
\hline 95,5 & 94,7 & 3,5 & 86,1 & 89 & 3,71 & 86,5 \\
\hline
\end{tabular}

Data Aktual 1 Hari Tanggal 19 Mei 2019

Tabel 4 Data parameter operasi tanggal 19 Mei 2019

\begin{tabular}{|c|c|c|c|}
\hline \multirow[b]{2}{*}{ Jam } & \multicolumn{3}{|c|}{ Unit 1} \\
\hline & $\begin{array}{l}\text { Daya } \\
{[\mathrm{kW}]}\end{array}$ & $\begin{array}{c}\text { Head } \\
{[\mathrm{m}]}\end{array}$ & $\begin{array}{l}\text { Debit } \\
{\left[\mathrm{m}^{3} / \mathrm{dt}\right]}\end{array}$ \\
\hline 00.00 & 1800 & 98 & 2,8 \\
\hline 01.00 & 1800 & 98 & 2,8 \\
\hline 02.00 & 1800 & 98 & 2,8 \\
\hline 03.00 & 1800 & 98 & 2,8 \\
\hline 04.00 & 1800 & 98 & 2,8 \\
\hline 05.00 & 1800 & 98 & 2,7 \\
\hline 06.00 & 1800 & 98 & 2,7 \\
\hline 07.00 & 1800 & 98 & 2,7 \\
\hline 08.00 & 1800 & 98 & 2,7 \\
\hline 09.00 & 1800 & 98 & 2,7 \\
\hline 10.00 & 1800 & 98 & 2,7 \\
\hline 11.00 & 1800 & 98 & 2,7 \\
\hline 12.00 & 1800 & 98 & 2,7 \\
\hline 13.00 & 2800 & 95 & 3,5 \\
\hline 14.00 & 2800 & 95 & 3,5 \\
\hline 15.00 & 2800 & 95 & 3,5 \\
\hline 16.00 & 2800 & 95 & 3,5 \\
\hline 17.00 & 2800 & 95 & 3,5 \\
\hline 18.00 & 2800 & 95 & 3,5 \\
\hline 19.00 & 3500 & 84 & 4,9 \\
\hline 20.00 & 3500 & 84 & 4,9 \\
\hline 21.00 & 3500 & 84 & 4,9 \\
\hline 22.00 & 1800 & 98 & 2,7 \\
\hline 23.00 & 1800 & 98 & 2,7 \\
\hline 24.00 & 1800 & 98 & 2,7 \\
\hline
\end{tabular}

Perhitungan Efisiensi Turbin

Dalam perhitungan efisiensi turbin kita perlu membandingkan daya mekanik dengan daya air atau daya potensial dari air. Dalam hal ini untuk daya mekanik telah didapatkan pada alat ukur yang terdapat pada Human Machine Interface (HMI) yang ada pada panel kontrol di PLTA Batang Agam.

Oleh sebab itu yang perlu dicari dalam perhitungan selanjutnya adalah daya potensial air dengan contoh perhitungan dari tabel 4.3 unit 1 pukul 00.00:

Diketahui:

$\rho=1000[1000 \mathrm{~kg} / \mathrm{m} 3] ; \mathrm{g}=9,81[\mathrm{~m} /$ detik2 $]$

$\mathrm{Q}=2,8[\mathrm{~m} 3 /$ detik $] \quad ; \mathrm{H}=98[\mathrm{~m}]$

Dengan menggunakan rumus,

Phid $=\rho \times g \times Q \times H$

Masukan nilai - nilai yang ada pada Tabel 4.3 data aktual untuk operasional turbin unit 1 .

Phid $=1000 \times 9,81 \times 2,8 \times 98$

Phid $=2.691 .864$ Watt

$$
=2,691 \mathrm{MW}
$$

Selanjutnya kita mencari efisiensinya dengan membandingkan daya mekanik dengan daya air.

$$
\begin{aligned}
\eta= & \frac{\text { Daya Mekarik }}{\text { Daya Air }} \times 100 \% \\
& =\frac{1,8}{2,691} \times 100 \% \\
& =66,86 \%
\end{aligned}
$$

Data Hasil Perhitungan

Setelah dilakukan perhitungan efisiensi didapatkan beberapa tabel perhitungan, diantaranya adalah: 
Tabel 5 Hasil perhitungan efisiensi turbin unit 1 pada tanggal 19 Mei 2019

\begin{tabular}{|c|c|c|}
\hline \multirow[b]{2}{*}{ Jam } & \multicolumn{2}{|c|}{ Unit 1} \\
\hline & $\begin{array}{l}\text { Daya } \\
{[\mathrm{kW}]}\end{array}$ & $\begin{array}{c}\text { Efisiensi } \\
{[\%]}\end{array}$ \\
\hline 00.00 & 1800 & 66,87 \\
\hline 01.00 & 1800 & 66,87 \\
\hline 02.00 & 1800 & 66,87 \\
\hline 03.00 & 1800 & 66,87 \\
\hline 04.00 & 1800 & 66,87 \\
\hline 05.00 & 1800 & 69,34 \\
\hline 06.00 & 1800 & 69,34 \\
\hline 07.00 & 1800 & 69,34 \\
\hline 08.00 & 1800 & 69,34 \\
\hline 09.00 & 1800 & 69,34 \\
\hline 10.00 & 1800 & 69,34 \\
\hline 11.00 & 1800 & 69,34 \\
\hline 12.00 & 1800 & 69,34 \\
\hline 13.00 & 2800 & 85,84 \\
\hline 14.00 & 2800 & 85,84 \\
\hline 15.00 & 2800 & 85,84 \\
\hline 16.00 & 2800 & 85,84 \\
\hline 17.00 & 2800 & 85,84 \\
\hline 18.00 & 2800 & 85,84 \\
\hline 19.00 & 3500 & 86,68 \\
\hline 20.00 & 3500 & 86,68 \\
\hline 21.00 & 3500 & 86,68 \\
\hline 22.00 & 1800 & 69,34 \\
\hline 23.00 & 1800 & 69,34 \\
\hline 24.00 & 1800 & 69,34 \\
\hline
\end{tabular}

Tabel 6 Hasil perhitungan efisiensi masingmasing turbin PLTA Batang Agam

\begin{tabular}{|c|c|c|c|c|c|c|c|c|c|}
\hline \multirow{2}{*}{$\begin{array}{c}\text { Daya } \\
{[\mathbf{M W}]}\end{array}$} & \multicolumn{3}{|c|}{ Turbin 1 } & \multicolumn{3}{|c|}{ Turbin 2 } & \multicolumn{3}{c|}{ Turbin 2 } \\
\cline { 2 - 12 } & Head & Debit & Eff. & Head & Debit & Eff. & Head & Debit & Eff. \\
\hline 1,8 & {$[\mathrm{~m} 3 / \mathrm{dt}]$} & & {$[\mathrm{m}]$} & {$[\mathrm{m} 3 / \mathrm{dt}]$} & & {$[\mathrm{m}]$} & {$[\mathrm{m} 3 / \mathrm{dt}]$} & \\
\hline 1,8 & 98 & 2,8 & 0,67 & 98 & 2,8 & 0,67 & 98 & 2,8 & 0,67 \\
\hline 2,3 & 97 & 3,2 & 0,76 & 97 & 3,5 & 0,69 & 97 & 3,5 & 0,69 \\
\hline 2,5 & 97 & 3,3 & 0,80 & 97 & 3,7 & 0,71 & 95 & 3,6 & 0,75 \\
\hline 2,8 & 95 & 3,7 & 0,81 & 95 & 4 & 0,75 & 95 & 4 & 0,75 \\
\hline 3 & 96 & 3,8 & 0,84 & 93 & 4,3 & 0,76 & 93 & 4,1 & 0,82 \\
\hline 3,5 & 84 & 4,9 & 0,87 & 85 & 5,3 & 0,79 & 85 & 5 & 0,84 \\
\hline
\end{tabular}

\section{Analisis Hasil Data}

Analisa Grafik saat Komisioning

Dari data pada tabel 7 yaitu ketika komisioning maka didapatkan berbagai macam grafik yang dapat digunakan untuk menganalisa unjuk kerja turbin pada saat komisioning.

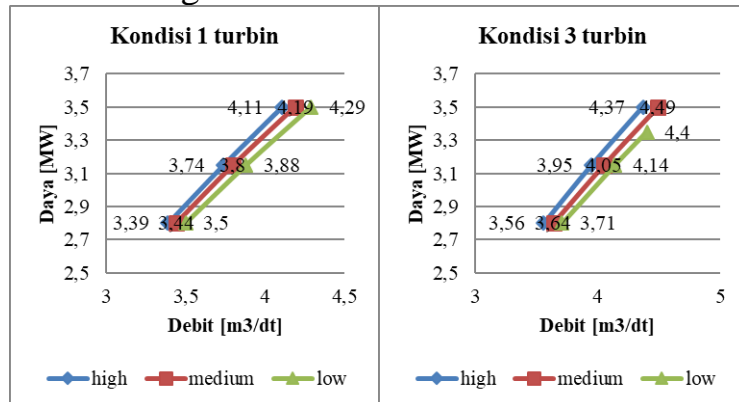

Gambar 6 Grafik perbandingan daya terhadap debit kondisi 1 turbin operasi dan 3 turbin operasi saat komisioning

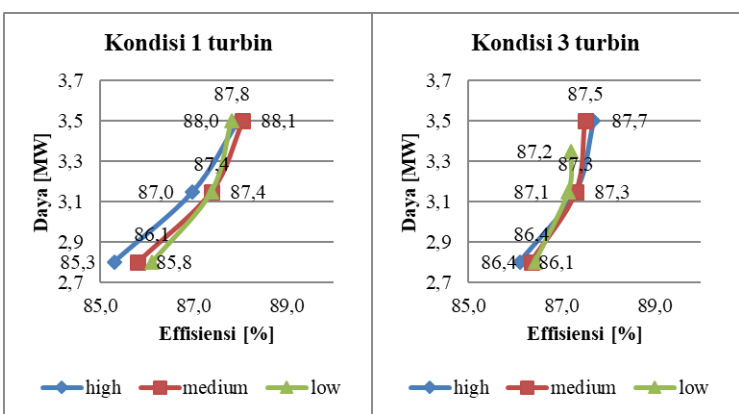

Gambar 7 Grafik perbandingan daya terhadap efisiensi kondisi 1 turbin operasi dan 3 turbin operasi saat komisioning 


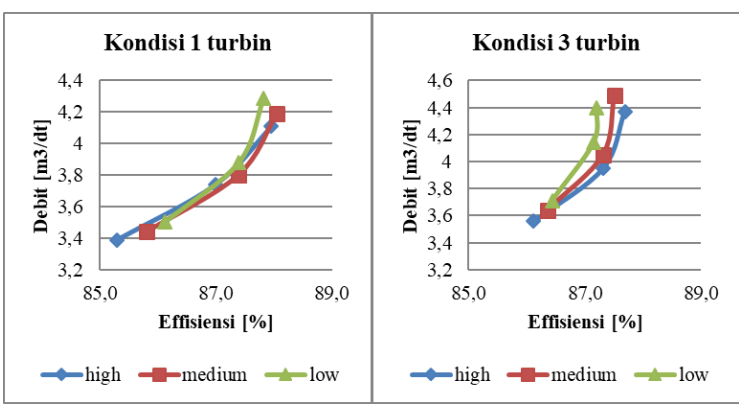

Gambar 8 Grafik perbandingan debit terhadap efisiensi kondisi 1 turbin operasi dan 3 turbin operasi saat komisioning

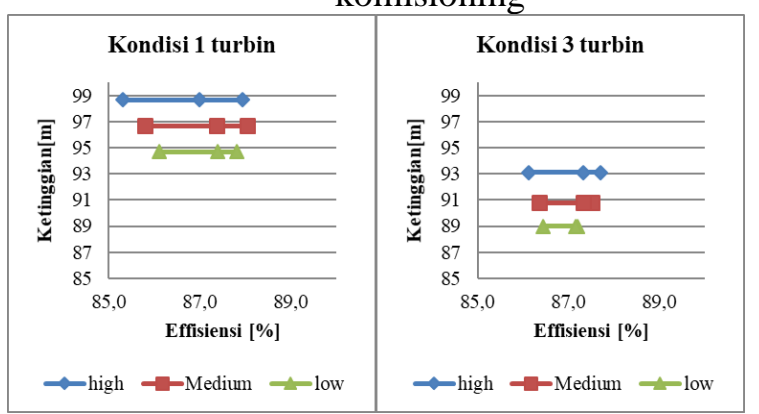

Gambar 9 Grafik perbandingan head terhadap efisiensikondisi 1 turbin operasi dan 3 turbin operasi saat komisioning

Analisa Unjuk Kerja Harian

Dari hasil pengambilan data dan perhitungan, maka bisa didapatkan grafik unjuk kerja operasi turbin unit 1 di tanggal 19 Mei 2019 dengan berbagai macam pola operasi dalam satu hari.

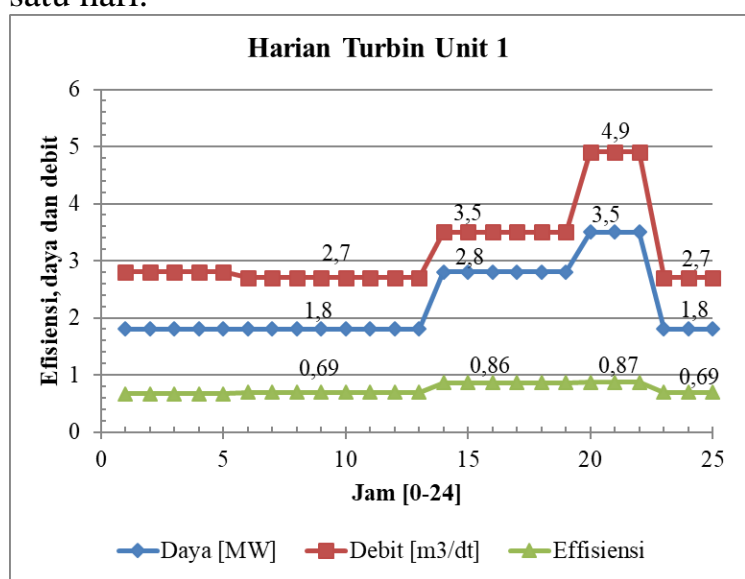

Gambar 10 Grafik unjuk kerja turbin unit 1
Analisa Unjuk Kerja 3 Unit Turbin

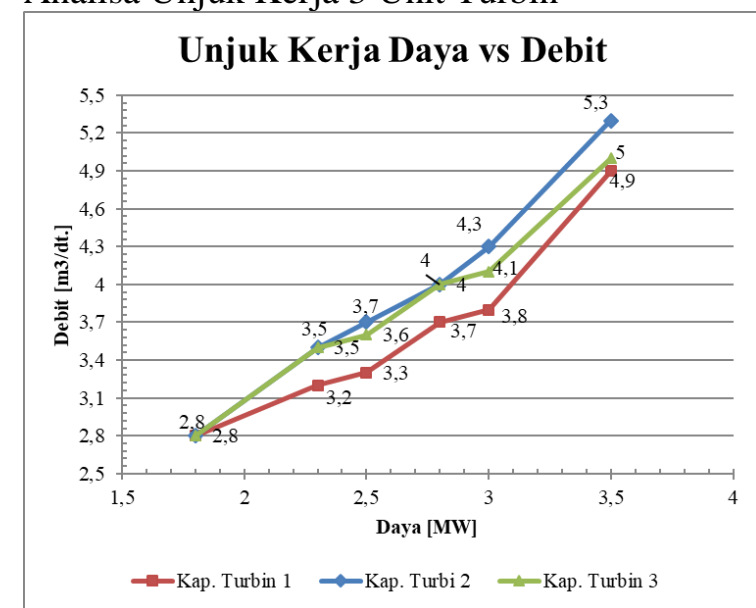

Gambar 11 Grafik perbandingan daya terhadap debit masing-masing unit

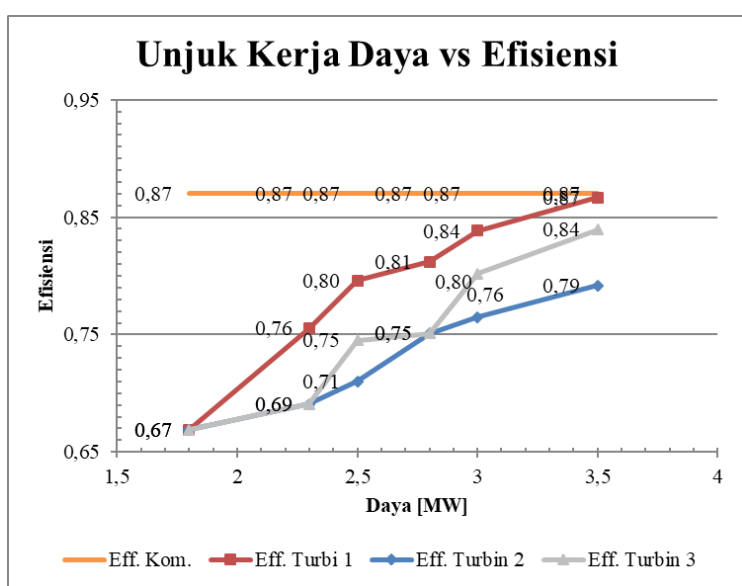

Gambar 12 Grafik perbandingan unjuk kerja masing-masing unit saat ini terhadap komisioning

\section{PENUTUP \\ Simpulan}

1) Setelah mendapatkan data-data dan telah dianalisa, maka didapatkan kesimpulan sebagai berikut:

2) Efisiensi turbin PLTA Batang Agam pada beban 3,5 MW dari yang paling tinggi ke yang paling rendah; Unit 1 dengan efisiensi $86,7 \%$, Unit 3 dengan efisiensi 83,9\% dan Unit 2 dengan efisiensi $79,2 \%$.

3) Dibandingkan dengan data komisioning unit - unit di turbin PLTA Batang Agam mengalami penurunan efisiensi sebesar; Unit 1 sebesar $0,32 \%$, Unit 2 sebesar 7,80\% dan Unit 3 sebesar 3,05\%.

Saran

Untuk menjaga kehandalan unit-unit di PLTA Batang Agam, khususnya turbin pada 
PLTA Batang Agam diwajibkan melaksanakan inspeksi peralatan-peralatan dengan jadwal yang telah ditentukan, sehingga gangguan dapat terdeteksi sejak dini.

\section{DAFTAR PUSTAKA}

Standards Of The Japanese Electrotechnical Committee, 1960, Hydarulic Turbines. Tokyo: Japan Electric Machine Industry Association.

Engineering Monographs, 1976, Selecting Hydraulic Reaction Turbines. Washington: U.S. Government Printing Office.

PT. PLN (PERSERO) Pusat Pendidikan Dan Pelatihan, Pemeliharaan Mesin-Turbin PLTA

Ebara. 1976. Final As Built Drawing. Japan : PLTA Batang Agam

Dietzel, F., dan Sriyono, D. (1990) Turbin, Pompa dan Kompresor, Erlangga, Jakarta

Luknanto, Djoko. Bangunan Tenaga Air.

Yogyakarta 